\title{
Editorial
}

Interational Archives of
Allergy
Immunology

Published online: December 18, 2013

DOI: $\underline{10.1159 / 000357188}$

\section{All of ARIA in One Puff?}

\author{
Ralph Mösges \\ Institute of Medical Statistics, Informatics, and Epidemiology, Medical Faculty, University of Köln, Cologne, Germany
}

It is a paradox of our specialty that more than a century after the definition of the term 'allergy', 100 years after the first clinical application of specific immunotherapy as causal treatment, 80 years after the discovery of antihistamines as acute remedies, and 50 years after the introduction of the first nasal steroid, more patients than ever are affected by the disease. Furthermore, the severity and the persistence of the disorder have increased in most individuals who are concerned, so that an expert group recognized the necessity to define a new clinical entity, namely the 'severe chronic upper airway disease' (SCUAD) [1]. In spite of all therapeutic innovations, there remains a hard core of allergic rhinitis patients who do not benefit from the current rhinitis management approaches defined in the latest ARIA (Allergic Rhinitis and Its Impact on Asthma) documents [2]. In a representative sample in the US population, the majority $(60 \%)$ of hay fever patients are still complaining about insufficient symptom control during the pollen season [3]. In fact, there are salvage therapies, for instance the administration of systemic steroids, for most severely affected patients, but they are not applicable on a permanent basis due to pronounced side effects. Similarly, although there are remarkable reports about the effects of the monoclonal antibody omalizumab, a widespread introduction of this upscale pharmacon would ruin our health care sys- tems, given the hundreds of millions of patients affected worldwide.

Many SCUAD patients feel abandoned by their allergists, and, as a consequence, the majority of European rhinitis patients do not consult their physician any more [4]. The flourishing market for alternative therapies in allergy speaks for itself.

Some years ago, Michael Kaliner [5], then president of the American Academy of Allergy, Asthma, and Immunology, claimed to have discovered the ultimate treatment for all types of rhinitis, be it allergic, nonallergic (Americans still use the term 'vasomotor' for this entity), or a mixed type of allergic rhinitis with nonallergic triggers like smoke or cold air. He proposed to use a combination of a nasal antihistamine and a nasal steroid. Since the scientific evidence for this approach was still missing at the time, they only smiled at his suggestion and insisted on their ARIA algorithm.

It took only 5 years to produce the evidence for Kaliner's concept and the drug stepping now into the worldwide arena claims to combine the entire ARIA guideline in one single nasal application. Antihistamine, mast cellstabilizing, and anti-leukotriene effects as well as steroidal properties have been described in clinical trials with the two compounds, fluticasone proprionate and azelastine hydrochloride. These two active ingredients therefore

\section{KARGER}

E-Mail karger@karger.com

www.karger.com/iaa
(C) 2013 S. Karger AG, Basel

$1018-2438 / 13 / 1633-0163 \$ 38.00 / 0$
Correspondence to: Prof. Ralph Mösges

Institute of Medical Statistics, Informatics, and Epidemiology

Medical Faculty, University of Köln

DE-50924 Köln (Germany)

E-Mail Ralph@ Moesges.de 
comprise all the pharmacological principles foreseen in the algorithm of the latest ARIA guideline. It was mandatory to put this theoretically sound approach to the clinical test and the results have been well received by the scientific public [6]. However, the problems of SCUAD patients remain unsolved. Meltzer et al. [7], who assessed the clinically relevant effect of this new intranasal therapy in allergic rhinitis by responder analysis, take credit for shedding light on this imminent challenge for every clinically oriented allergist. Although they did not perform new clinical trials, they were able to test, based upon predefined criteria of success, the a priori hypothesis of a more relevant clinical effect of the new therapeutic entity against placebo. They re-analyzed a patient population suffering from severe rhinitis, which also included a SCUAD population [8]. Their responder sensitivity analyses are innovative, yet necessary, owing to the fact that EMA (European Medicines Agency) as regulatory body questions the clinical relevance of a simple change from baseline in the total nasal symptom score. In their guidelines, EMA suggests a clinically meaningful response without clearly defining what exactly that would be. In their paper, the authors determine different response cutoffs from 30 to $90 \%$. They are able to demonstrate that even in patients who are most severely and most persistently affected, a meaningful improvement in the state of their disease occurs following the combination treatment. It could not be expected that part of a typical nonresponder collective would experience such a relief of their very pronounced complaints within the typical 2-week observation period. The remainder of patients whose disease is refractory to the classical monotherapies, usually $30-50 \%$, may therefore experience a significant reduction in their symptoms with the new approach.

This analysis is based upon data of a previously published clinical trial. The authors do not claim to create clinical evidence as a meta-analysis offers. Indeed, it is not a meta-analysis like the one that has already been published for this new therapeutic option [9] but was conducted post hoc. However, since the criteria were predefined, the approach of a responder analysis may add new insights into the management of a hard-to-treat population of severe sufferers. Twelve years after the first ARIA document, it may confirm the concept that was then set forth without experimental evidence. Also, this new coherent therapeutic option may open a door to address a large number of patients formerly dissatisfied with their allergists. Once they have regained confidence in the therapeutic opportunities we offer, they may be open to opt for the most comprehensive treatment concept that we have: specific immunotherapy.

And then, it would in fact be all of ARIA put together.

\section{References}

$\checkmark 1$ Bousquet J, Bachert C, Canonica GW, Casale TB, Cruz AA, Lockey RJ, Zuberbier T, Extended Global Allergy and Asthma European Network, World Allergy Organization and Allergic Rhinitis and Its Impact on Asthma Study Group: Unmet needs in severe chronic upper airway disease (SCUAD). J Allergy Clin Immunol 2009;124:428-433.

- 2 Bousquet J, Schünemann HJ, Samolinski B, et al: Allergic Rhinitis and Its Impact on Asthma (ARIA): achievements in 10 years and future needs. J Allergy Clin Immunol 2012;130:1049-1062.

-3 Derebery J, Meltzer E, Nathan RA, Stang PE, Campbell UB, Corrao M, Stanford R: Rhinitis symptoms and comorbidities in the United States: burden of rhinitis in America survey. Otolaryngol Head Neck Surg 2008;139:198205.
4 Maurer M, Zuberbier T: Undertreatment of rhinitis symptoms in Europe: findings from a cross-sectional questionnaire survey. Allergy 2007;62:1057-1063.

5 Kaliner MA: A novel and effective approach to treating rhinitis with nasal antihistamines. Ann Allergy Asthma Immunol 2007;99:383390.

6 6 Leung DYM, Szefler SJ, Associate Editors of the JACI: The Editors' choice. J Allergy Clin Immunol 2012;129:1216-1217.

7 Meltzer E, Ratner P, Bachert C, Carr W, Berger W, Canonica GW, Hadley J, Lieberman $P$, Hampel FC, Mullol J, Munzel U, Price D, Scadding G, Virchow JC, Wahn U, Murray R, Bousquet J: Clinically relevant effect of a new intranasal therapy (MP29-02) in allergic rhinitis assessed by responder analysis. Int Arch Allergy Immunol 2013;161:369-377. NJ, Daftary P, Wheeler W, Sacks H: Doubleblind, placebo-controlled study of azelastine and fluticasone in a single nasal spray delivery device. Ann Allergy Asthma Immunol 2010; 105:168-173.

$\checkmark$ Carr W, Bernstein J, Lieberman P, Meltzer E, Bachert C, Price D, Munzel U, Bousquet J: A novel intranasal therapy of azelastine with fluticasone for the treatment of allergic rhinitis. J Allergy Clin Immunol 2012;129:12821289. 